\title{
Disrespect and abuse during facility-based childbirth in Pokhara metropolitan city
}

\author{
Rekha Thapaliya*, Kalpana Paudel, Saphalta Shrestha
}

Tribhuvan University, Institute of Medicine, Pokhara Nursing Campus, Pokhara, Nepal

\begin{abstract}
Introduction: Respectful maternity care is the universal right of every childbearing woman, which promotes the practices that recognize women's preferences and women's and newborns' needs. The objective of the study was to assess disrespect and abuse during facility-based childbirth in Pokhara. Methods: Postnatal mothers having vaginal institutional delivery were included in the study. Non-probability purposive sampling technique was done to select 231 samples. Face to face interview technique with structured interview schedule was used. Descriptive and inferential statistics were used for data analysis. Results: Most (88.3\%) of the mothers were between the age of 20 and 34 years with the mean age of $25.39 \pm 4.799$ years. More than half of them had spontaneous vaginal delivery with episiotomy and (87\%) of mothers had no any complications during childbirth. The overall disrespect and abuse during facility-based childbirth was (70.1\%) and only (29.9\%) of the postnatal mothers received respectful and non-abusive care. Regarding types of disrespect and abuse, (34.6\%) of them were suffered from physical abuse, (68\%) received non-consented care, (22.5\%) of them received non-confidential and non-dignified care, $(1.3 \%)$ experienced discrimination based on specific attributes and (26\%) suffered from abandonment or neglect of care. There was no significant association between the prevalence of disrespect and abuse with socio-demographic and obstetric characteristics of the mothers. The association was found with place of delivery. Conclusion: It is concluded that near to three fourth of the postnatal mothers suffer from disrespect and abuse during facility based child birth in Pokhara. Thus, to increase respectful and non-abusive care during facility based childbirth, practice of respectful maternity care should be promoted including development of clinical guidelines and protocols.
\end{abstract}

Keywords: Childbirth, Disrespect and Abuse, Facility, Pokhara

\section{*Correspondence:}

Ms Rekha Thapaliya

Lecturer, Tribhuvan University, Institute of Medicine, Pokhara Nursing Campus, Pokhara, Nepal

Email: rekha363845@gmail.com

Submitted: August 8, 2020

Accepted: February 18, 2021

To cite: Thapaliya R, Paudel K, Shrestha S. Disrespect and abuse during facility- based childbirth in Pokhara metropolitan city. JGMC Nepal. 2021;14(1):39-44.

DOI: $10.3126 /$ jgmcn.v14i1.30572

\section{INTRODUCTION}

The White Ribbon Alliance is a worldwide movement for safe motherhood that believes that respectful maternity care is the universal right of every childbearing woman, considers disrespect and abuse during maternity care as a violation of women's basic human rights. ${ }^{1}$ Respectful maternity care is an approach centered on the individual, based on principles of ethics and respect for human rights, and promotes practices that recognize women's preferences and women's and newborns' needs. ${ }^{2}$

Bowser and Hill $2010,{ }^{3}$ in a landscape analysis, categorized disrespectful and abusive care at childbirth into seven types: physical abuse, non-consented care, non-confidential care, non-dignified care, discrimination, abandonment of care and detention in facilities. Bohren et al. ${ }^{4}$ in their systematic review further classified mistreatment of women during facility-based childbirth into seven domains: physical abuse, sexual abuse, verbal abuse, stigma and discrimination, failure to meet professional standard of care, poor rapport be- 
tween women and providers, and health system conditions and restraints.

A study conducted in Nigeria among 446 mixed rural and urban women showed that 98 percent of women reported at least one kind of abuse and disrespect during their last childbirth. The provision of non-consented services and physical abuse were the most common types of disrespectful and abusive care during facility-based childbirth. ${ }^{5}$ Similarly study conducted in Tanzania, evidence from direct observations of client-provider interactions during labor and delivery confirmed high rates of some disrespectful and abusive behaviors. ${ }^{6}$ The most frequently mentioned form of disrespect and abuse in the open-ended comments were abandonment and neglect. ${ }^{7}$

The extent of disrespect and abuse in facility-based childbirth has not been systematically documented or even well defined. Women's health and human rights experts believe that disrespect and abuse in childbirth represents an important barrier to utilization of skilled birth care and constitutes a common cause of suffering and violations of human rights of women. ${ }^{8,9}$ It also damages the trust between the woman and healthcare providers and effects on decision making regarding future delivery in a health facility including quality of care. ${ }^{10,11}$ So, this study aimed to determine the prevalence and types of disrespect and abuse postnatal mothers experienced during facility based childbirth in Pokhara.

\section{METHODS}

The descriptive cross sectional study design was used to determine the prevalence of disrespect and abuse during facility-based childbirth in Pokhara Metropolitan City. It has 33 numbers of wards. Pokhara Metropolitan City office runs their mobile clinic of maternal and child health services from ward number one to seventeen. Most of the wards belongs to ward number one to seventeen provide service once a month in respective day like ward number one in first day of month. Immunization clinic of ward number eighteen to thirty-three are run by health center of respective wards on $4^{\text {th }}, 5^{\text {th }}, 6^{\text {th }}$ and $7^{\text {th }}$ of every month. The postnatal mothers who were attending Maternal and Child Health Clinic of respective ward for any purpose within 45 days of delivery were the study population. Sample size was determined by using the Cochrane's formula, $n$ $=\left(\mathrm{Z} \alpha^{2} \mathrm{pq}\right) / \mathrm{d}^{2}$. Information regarding number of postnatal mothers visiting the clinic per day from each ward of the Pokhara Metropolitan City was obtained. The average number of postnatal mothers visiting the clinic per day was 50. Non-probability purposive sampling technique was used to collect the sample of 231 postnatal mothers. Seven postnatal mothers were taken from each ward. The postnatal mothers having vaginal institutional delivery were included in the study. Women having cesarean section for their child birth and home delivery were excluded.

A structured interview schedule was constructed by the researcher through extensive literature review. The first part included the questions about socio-demographic characteristics and the second part included the questions related to obstetrics characteristics. The third part included the questions related to disrespect and abuse. The level of disrespect and abuse was measured on the basis of seven performance standards (categories of disrespect and abuse) and their respective verification criteria developed by the Maternal and Child Health Integrated Program (MCHIP) as part of their respectful maternity care tool kit. ${ }^{2}$ The performance standards were physical abuse (7 items), non-consented care (12 items), non-confidential care (4 items), non -dignified care (4 items), discrimination based on specific attributes (5 items), abandonment/neglect of care ( 3 items) and detention in facilities ( 1 item). A total of 36 verification criteria of disrespect and abuse were used in the study. Verification criteria were counted within their respective categories of disrespect and abuse. The verification criteria were dichotomized responses, "Yes" or "No", to objectively identify reported events of disrespect and abuse. For categories of disrespect and abuse with one or more than one verification criterion, a woman was labeled as "disrespected and abused in the respective category" if she reported "Yes" to at least one of the verification criteria during childbirth. If a mother was identified as having faced disrespected and abused in at least one of the seven categories, she was considered "disrespected and abused".

Data was collected after getting ethical approval from Institutional Review Committee of Institute of Medicine and Office of Pokhara Metropolitan. The IRC approval reference number is $420(6-11) \mathrm{e}^{2} / 075 / 76$. Purpose of the study was explained to the respondents. An informed written consent was obtained from each subject prior to data collection. The respondents were assured voluntary participation. Confidentiality of the information was maintained by not disclosing the information and using the obtained information for the study purpose only. The data was collected from $14^{\text {th }}$ May to June $13^{\text {th }}, 2019$ through face to face interview technique.

The collected data was edited, organized, coded and analyzed using computer package with SPSS (Statistical Package for Social Science) software version 16. Data was 
analyzed by using descriptive and inferential statistics. Descriptive statistics i.e., frequency, percentage, mean, range, standard deviation was computed for the study variables. Inferential statistics i.e., Chi square and Fisher's exact test were used to find out the association. P value of $<0.05$ was considered significant.

\section{RESULTS}

Two hundred and thirty-one postnatal mothers attending Maternal and Child Health Clinic were included in the study. Most (88.3\%) of the mothers were between the age of 20 and 34 years. The mean age was $25.39 \pm 4.799$ years ranging from 16 to 40 years. Regarding ethnicity, $45.5 \%$ of the mothers were Janajati and more than one third (33.8\%) were Brahmin/Chhetri. All of them were literate. More than half (68.8\%) were home maker. Regarding occupation of their husbands, more than half were involved in private job. More than half (64.9\%) of the mother's family income was adequate for more than one year with surplus. Majority $(72.3 \%)$ of the mothers delivered on government hospital and most (86.1\%) of them would recommend the facilities for their family and friends (Table 1). More than half of the mothers belong to multiparous, $56.7 \%$ had spontaneous vaginal delivery with episiotomy whereas $7.4 \%$ had assisted vaginal delivery (vacuum). Most (90.5\%) of the mother's new born baby was born without complications and majority (87\%) of the mothers had no any complications during childbirth (Table 2).

In this study, $65.4 \%$ of the postnatal mothers were not physically abused whereas $34.6 \%$ of them were physically abused during facility based child birth. Likewise, on the aspects of the non-consented care, $68 \%$ of the mothers received non-consented care and $32 \%$ received consented care. Similarly, in non-confidential care more than three fourth $(77.5 \%)$ of the mothers had received confidential care whereas, $22.5 \%$ received non-confidential care. Likewise, $77.5 \%$ of the mothers were treated with dignity and respect, only $22.5 \%$ were not treated with dignity and respect. Regarding discrimination based on specific attributes most (98.7\%) of the mothers were not discriminated. Similarly, $74 \%$ of the mothers were never left without care and attention and only $26 \%$ were left without care and attention. Cent percent of mothers were never detained or confined against her will. The overall disrespect and abuse during facility-based childbirth was $70.1 \%$ and only $29.9 \%$ of the postnatal mothers received respectful non-abusive care (Table 3). There was not significant association between the prevalence of disrespect and abuse during facility-based childbirth with socio-demographic and obstetric characteristics of the mothers but significant association was found with place of delivery (Table 4).

Table 1: Background information of the mothers $(n=231)$

\begin{tabular}{|c|c|c|}
\hline Characteristics & Frequency & Percentage \\
\hline \multicolumn{3}{|l|}{ Age group in years } \\
\hline Less than 20 years & 21 & 9.1 \\
\hline 20-34 years & 204 & 88.3 \\
\hline 35 years and above & 6 & 2.6 \\
\hline \multicolumn{3}{|c|}{ Mean SD: 25.394 .799 years, Range: $16-40$ years } \\
\hline \multicolumn{3}{|l|}{ Ethnicity } \\
\hline Brahmin/Chhetri & 78 & 33.7 \\
\hline Janajati & 105 & 45.5 \\
\hline Dalit & 37 & 16.0 \\
\hline Marginalized group & 11 & 4.8 \\
\hline \multicolumn{3}{|l|}{ Types of family } \\
\hline Nuclear & 81 & 35.1 \\
\hline Joint & 150 & 64.9 \\
\hline \multicolumn{3}{|l|}{ Educational level } \\
\hline Primary level & 21 & 9.1 \\
\hline Secondary level & 80 & 34.6 \\
\hline Higher secondary level & 97 & 42.0 \\
\hline Bachelor level and above & 33 & 14.3 \\
\hline \multicolumn{3}{|l|}{ Occupational status of women } \\
\hline Agriculture & 5 & 2.3 \\
\hline Home maker & 159 & 68.8 \\
\hline Business & 41 & 17.7 \\
\hline Service & 25 & 10.8 \\
\hline Labour & 1 & 0.4 \\
\hline \multicolumn{3}{|l|}{ Husband Occupation } \\
\hline Government job & 30 & 13.0 \\
\hline Private job & 128 & 55.4 \\
\hline Jobless & 13 & 5.6 \\
\hline Foreign employment & 60 & 26.0 \\
\hline \multicolumn{3}{|l|}{ Status of the family income } \\
\hline Income enough only for less than six months & 4 & 1.7 \\
\hline Income enough for less than one year & 77 & 33.4 \\
\hline Income enough for one year and surplus. & 150 & 64.9 \\
\hline \multicolumn{3}{|l|}{ Place of delivery } \\
\hline Government hospital & 167 & 72.3 \\
\hline Private hospital & 64 & 27.7 \\
\hline \multicolumn{3}{|l|}{ Recommendations } \\
\hline Yes & 199 & 86.1 \\
\hline No & 32 & 13.9 \\
\hline
\end{tabular}


Table 2: Obstetric characteristics of the mothers $(n=231)$

\begin{tabular}{lcc}
\hline Characteristics & Frequency & Percentage \\
Parity & & \\
Primiparous & 114 & 49.4 \\
Multiparous & & 50.6 \\
Mode of present delivery & 29 & \\
Spontaneous Vaginal Delivery with intact perine- & 54 & 12.6 \\
um & & 23.3 \\
Spontaneous vaginal delivery with tear & 131 & 56.7 \\
Spontaneous vaginal delivery (SVD) with episiot- & 17 & 7.4 \\
omy & & \\
Assisted vaginal delivery (Vacuum) & 52 & 22.5 \\
Duration of labour pain & 100 & 43.3 \\
Less than six hours & 72 & 31.2 \\
6 to 12 hours & 7 & 3.0 \\
12 to 24 hours & & \\
More than 24 hours & 22 & 9.5 \\
Complications of new born & 209 & 90.5 \\
Yes & & \\
No & 30 & 13.0 \\
Complications of mother & 201 & 87.0 \\
Yes & & \\
No & & \\
\hline
\end{tabular}

Table 3: Prevalence of disrespect and abuse during facility-based childbirth $(n=231)$

\begin{tabular}{lcc}
\hline Disrespect and abuse & $\begin{array}{c}\text { Present } \\
\mathbf{n}(\%)\end{array}$ & $\begin{array}{c}\text { Absent } \\
\mathbf{n}(\%)\end{array}$ \\
Physical abuse & $80(34.6)$ & $151(65.4)$ \\
Non- consented care & $157(68.0)$ & $74(32.0)$ \\
Non-confidential care & $52(22.5)$ & $179(77.5)$ \\
Non-dignified care & $52(22.5)$ & $179(77.5)$ \\
Discrimination based on specific attributes & $3(1.3)$ & $228(98.7)$ \\
Abandonment/neglect of care & $60(26.0)$ & $171(74.0)$ \\
Detention in health facilities & $0(0.0)$ & $231(100.0)$ \\
Overall prevalence of disrespect and abuse* & $162(70.1)$ & $69(29.9)$ \\
\hline
\end{tabular}

*Mothers who faced disrespect and abuse in at least one among the seven categories

Table 4: Association of prevalence of disrespect and abuse with place of delivery

\begin{tabular}{lcccc}
\hline $\begin{array}{l}\text { Prevalence of disrespect } \\
\text { and abuse during child- } \\
\text { birth by categories }\end{array}$ & $\begin{array}{c}\text { Government } \\
\text { Hospital } \\
\text { (n=167) } \\
\mathbf{f ~ ( \% )}\end{array}$ & $\begin{array}{c}\text { Private } \\
\text { Hospital } \\
\text { (n=64) } \\
\mathbf{f ~ ( \% )}\end{array}$ & Chi square & P value \\
Physical abuse & $67(40.1)$ & $13(20.3)$ & 8.001 & 0.005 \\
$\begin{array}{l}\text { Non-consented care } \\
\text { Non-confidential care }\end{array}$ & $126(75.4)$ & $31(48.4)$ & 15.5 & $<0.001$ \\
$\begin{array}{l}\text { Non -dignified care } \\
\text { Discrimination based on }\end{array}$ & $43(27.5)$ & $6(9.4)$ & 8.7 & 0.003 \\
specific attributes & $2(1.2)$ & $1(1.6)$ & Fisher Exact & test \\
$\begin{array}{l}\text { Abandonment/neglect of care } \\
\text { Detention in health facilities }\end{array}$ & $50(29.9)$ & $10(15.6)$ & 4.9 & 0.026 \\
$\begin{array}{l}\text { Overall disrespect and } \\
\text { abuse }\end{array}$ & - & - & - & - \\
\hline
\end{tabular}

$\mathrm{P}$ value is significant at $\leq 0.05$

\section{DISCUSSION}

Every woman has right to give birth in the institution free from disrespect and abuse. The disrespect and abuse can be a barrier to utilization of facility for childbirth. In the current study $34.6 \%$ of the mothers were suffered from physical abuse during facility based child birth which was consistent with the findings of study conducted in Ethiopia $^{12}$ and contrast with the study done in Tanzania. ${ }^{6}$ Present study demonstrates $68 \%$ of the mothers received non consented care on the aspects of the woman's right to information, informed consent, and choice/preferences. This finding was lower than the findings of the previous study conducted in Ethiopia, which showed $90 \%{ }^{13}$

Present study explains more than three fourth (77.5\%) of mothers had received confidential care and only $22.5 \%$ of them received non confidential care which was similar to previous study conducted by Okafor et al..$^{5}$ and study of Asefa et al. ${ }^{12}$ In the current study $77.5 \%$ of the mothers were treated with dignity and respect and only $22.5 \%$ were not treated with dignity and respect which was consistent with findings of Okafor et al. ${ }^{5}$ but in contrast with Sando et al. ${ }^{6}$ which showed that $8.0 \%$ were treated with dignity and respect.

In the present study, most (98.7\%) of the mothers were not discriminated based on specific attributes. The finding contrasted with the findings of the previous study done by Asefa et al. ${ }^{12}$ which was $19.7 \%$. Similarly, $74.0 \%$ of the mothers were never left without care and attention and only $26.0 \%$ were left without care and attention which was consistent with the previous study conducted by Okafor et al. ${ }^{5}$ and Sheferaw et al. ${ }^{14} \mathrm{All}$ of mothers were never detained or confined against her will whereas study conducted in India showed 3.3\% were detained or confined against her will. ${ }^{15}$

In the present study, the overall disrespect and abused reported during facility-based childbirth was $70.1 \%$. The prevalence of disrespect and abuse was contradicted with findings of the previous study conducted by Sando et al. ${ }^{6}$ which was $15 \%$, but similar to findings of the previous study conducted by Asefa et al. ${ }^{12}$ This prevalence is high and comparable to those reported in Tanzania 70\%, ${ }^{6}$ India $84.3 \%,{ }^{15}$ Ethiopia $91.7 \%,{ }^{13}$ Pakistan $97 \%{ }^{16}$ and Nigeria $98 \% .{ }^{5}$ The findings of this study showed $29.9 \%$ of postnatal mothers had received respectful and non-abusive care. The prevalence of respectful and non-abusive care is lower than the findings of the previous study conducted in Ethiopia, which was $57 \%{ }^{17}$ 
This study did not show significant association between the prevalence of disrespect and abuse with age, occupation, education, ethnicity, religion and family type. This finding was similar to the findings of the previous study conducted by Nawab et al. ${ }^{15}$ In the present study, there was significant association between the prevalence of disrespect and abuse during facility-based childbirth and place of delivery. This finding was supported by the previous study done in Pakistan. ${ }^{18}$

\section{CONCLUSION}

Near to three fourth of postnatal mothers were suffered from disrespect and abuse during facility based child birth in Pokhara. Regarding types of disrespect and abuse, more than one third was physical abuse, more than two third received non-consented care, near to one fourth received non-confidential and non-dignified care. More than one fourth left without care and attention. Thus, to increase respectful and non-abusive care during facility-based childbirth, practice of respectful maternity care should be promoted including development of clinical guidelines and protocols.

\section{Financial support and sponsorship}

Rector's office, Tribhuvan University, Kirtipur, Kathmandu, Nepal

Conflict of Interest: There is no conflict of interest.

\section{REFERENCES}

1. The White Ribbon Alliance for Safe Motherhood. Respectful maternity care: the universal rights of childbearing women. White Ribbon Alliance. 2011. Available from: http:// whiteribbonalliance.org/wpcontent/uploads/2013/10/ Final_RMC_Charter.pdf [Accessed $15^{\text {th }}$ January 2019].

2. United States Agency for International Development. Respectful maternity care country experiences. USAID; 2012. Available from:https://toolkits.knowledgesuccess. org/sites/default/files/rmc_survey_report_0_0.pdf [Accessed $15^{\text {th }}$ January 2019].

3. Bowser D, Hill K. Exploring Evidence for Disrespect and Abuse in Facility-Based Childbirth Report of a Landscape Analysis. Washington, D.C.: USAID Translating Research into Action (TRAction) Project: Harvard School of Public Health, and University Research Co. 2010. Available from: https://www.ghdonline.org/uploads/Respectful_Care_at_ Birth_9-20-101_Final1.pdf [Accessed $4^{\text {th }}$ February 2019].

4. Bohren MA, Vogel JP, Hunter EC, Lutsiv O, Makh SK, Souza J. The Mistreatment of Women during Childbirth in Health
Facilities Globally: A Mixed-Methods Systematic Review. PLoS medicine. 2015;12(6). DOI: 10.1371/journal. pmed.1001847 PMID: 26126110.

5. Okafor II, Ugwu EO, Obi SN. Disrespect and abuse during facility-based childbirth in a low-income country. Int J Gynaecol Obstet. 2015;128 (2):110-113. DOI: 10.1016/j. ijgo.2014.08.015

6. Sando D, Ratcliffe H, McDonald K, Spiegelman D, Lyatuu G, Mwanyika-Sando M, et al. The prevalence of disrespect and abuse during facility-based childbirth in urban Tanzania. BMC Pregnancy Childbirth. 2016;16(1):236. DOI: 10.1186/s12884-016-1019-4

7. Heather ER, Pamela FL, Catherine C, Veronica R, Jim R, Eva $\mathrm{SB}$, Linda $\mathrm{AB}$. Direct observation of respectful maternity care in five countries: a cross-sectional study of health facilities in East and Southern Africa. BMC Pregnancy and Childbirth. 2015;15:306. DOI: 10.1186/s12884-015-07284

8. Miller S, Lalonde A. The global epidemic of abuse and disrespect during childbirth: history, evidence, interventions, and FIGO's mother-baby friendly birthing facilities initiative. International Journal of Gynecology and Obstetrics. 2015;131:49-52. DOI: 10.1016/j. ijgo.2015.02.005

9. World Health Organization. The prevention and elimination of disrespect and abuse during facility-based childbirth, World Health Organization. Geneva; Switzerland. WHO. 2015. Available from:http://apps.who.int/iris/bitstream/ handle/10665/134588/WHO_RHR_14.23_eng.pdf? sequence $=1$ [Accessed $25^{\text {th }}$ January 2019].

10. Galle A, Manaharlal H, Cumbane E, Picardo J, Griffin S, Osman N, et al. Disrespect and abuse during facility-based childbirth in southern Mozambique: a cross-sectional study. BMC Pregnancy Childbirth. 2019;19:369. DOI: 10.1186/s12884-019-2532-z

11. Moyer CA, Adongo PB, Aborigo RA, Hodgson A, Engman CM. 'They treat you like you are not a human being': Maltreatment during labour and delivery in rural northern Ghana. Midwifery. 2014;30(2):262-268. DOI: 10.1016/j. midw.2013.05.006

12. Asefa A, Bekele D. Status of respectful and non-abusive care during facility-based childbirth in a hospital and health centers in Addis Ababa, Ethiopia. Reproductive Health. 2015;12:33. DOI: 10.1186/s12978-015-0024-9

13. Siraj A, Teka W, Hebo H. Prevalence of disrespect and abuse during facility based child birth and associated factors, Jimma University Medical Center, Southwest Ethiopia. BMC Pregnancy and Childbirth. 2019;19:185. DOI: 10.1186/ 


\section{s12884-019-2332-5}

14. Sheferaw ED, Bazant E, Gibson H, Fenta HB, Ayalew F, Belay $\mathrm{TB}$, et al. Respectful maternity care in Ethiopian public health facilities. Reprod Health. 2017;14:60. DOI: 10.1186/ s12978-017-0323-4

15. Nawab T, Erum U, Amir A, Khalique N, Ansari MA, Chauhan A. Disrespect and abuse during facility-based childbirth and its sociodemographic determinants - A barrier to healthcare utilization in rural population. J Family Med Prim Care. 2019;8:239-45. DOI: 10.4103/jfmpc.jfmpc_247_18

16. Hameed W, Avan BI. Women's experiences of mistreatment during childbirth: A comparative view of home- and facility- based births in Pakistan. PLoS ONE. 2018;13(3). DOI: 10.1371/journal.pone.0194601

17. Wassihun B, Zeleke S. Compassionate and respectful maternity care during facility based child birth and women's intent to use maternity service in Bahir Dar, Ethiopia. BMC Pregnancy and Childbirth. 2018;18:294. DOI: 10.1186/ s12884-018-1909-8

18. Azhar Z, Oyebode O, Masud H. Disrespect and abuse during childbirth in district Gujrat, Pakistan: A quest for respectful maternity care. PLoS One. 2018;13(7). DOI: 10.1371/ journal.pone.0200318 